\title{
RE-EVALUATION OF CHARACTERISATION AND CLASSIFICATION OF APA (AFZELIA BIPINDENSIS) TIMBER FOR STRUCTURAL USE
}

\author{
A. A. JImoh ${ }^{1,}{ }^{*}$ and J. B. Adefemi ${ }^{2}$ \\ 1,2DEPARTMENT OF CIVIL ENGINEERING, UNIVERSITY OF ILORIN, ILORIN, KWARA STATE, NIGERIA. \\ Email addresses: ${ }^{1}$ aajimoh4real@yahoo.com, ${ }^{2}$ adfemjossy@yahoo.com
}

\begin{abstract}
.
As a result of effect of geographical location on timber properties, there is need for constant determination of properties of timber. This paper presents the results of experimental tests carried out on three Apa (Afzelia bipindensis) timber logs grown in Kwara State, south-western periphery of the North Central Zone of Nigeria in order to ascertain its structural strength properties. Logs of Apa timber were air-dried and along the stem, 324 pieces of test specimens were prepared for determination of their strength properties using a universal testing machine (UTM) FS50AT model, (specimen prepared included 108 samples for tensile strengths parallel to grain, 108 samples for compression parallel to grain and 108 samples for bending parallel to grain) at a moisture content of 12\%, in accordance with the Nigerian, British and European standards. The moisture content of $12 \%$ was converted to $18 \%$ which is specified in a standard document, for the area. Statistical analysis was carried out using the strength properties for determination of mean, standard deviation, confidence limit and characteristic strength. The result revealed that the timber is satisfactory for structural purposes in construction works.
\end{abstract}

Key words: Apa, bending strength, classification, compressive strength, structural use

\section{INTRODUCTION}

Timber is one of the most frequently used building materials in the construction industry. Despite the discovery and availability of other materials, the use of timber structure keeps increasing, due to its environmentally friendly nature, sustainability and low handling cost. Nevertheless, insufficient information on the structural behaviour of timber members and systems cause difficulties in adequate description and reliable design of timber structures [6].

Apa, botanical name: Afzelia bipindensis, is grown within the North central zone of Nigeria at the southwestern periphery of the rain forest [3]. It is readily available and extensively used in this area and other places in Nigeria, when transported. The use to which a timber member is subjected to determines its loading conditions and this in effect constitutes its structural integrity. There is need for sufficient information on the structural viability and market accessibility of timber species of interest, to ensure adequate use of the timber as construction material. It is a known fact that timber has a high strength to weight ratio, its strength and stiffness are dependent on the direction of load in relation to the grain and it is strong and relatively stiff parallel to the grain [7]. It was classified as a grade $\mathrm{N}_{2}$ timber [3]. This classification was based on a specification [2]. This classification entails that the timber is naturally very durable with moderate resistance to preservative impregnation and small movement properties when adequately seasoned.

The physical and mechanical properties of wood vary markedly, both within a tree and among trees and from sample to sample [8]. For evaluation of structural properties of timber, the determination of physical and mechanical properties of timber is important. The determination of strength characteristics of Apa timber involves the evaluation of the physical, mechanical and the structural properties of Nigerian grown Apa timber and the interrelationship of these properties. This study involved the evaluation of Nigerian grown Apa timber on the basis of its conformity to the required specifications [1-5]. Comparison will also be made between Nigerian grown Apa timber and others grown outside the shores of Nigeria.

The main challenge to a reliable design of timber as a structural member is to be acquainted with sufficient data about a given species of timber to ensure that the relevant performance criteria are met, as specified in 
the relevant standards and codes. This implies that failure risk is reduced to the extent to which structural information about a given species of timber is readily available to timber designers, specifiers and construction regulators. A significant element of uncertainty is associated with lack of information on the physical variability as well as structural behaviour of material under load, [9]. The study of strength characteristic of Apa timber is therefore aimed at reducing the structural risk of using the timber for supporting and sustaining loads in structural systems; while also updating the earlier classifications of this timber by both the British and the Nigerian codes to the current British and European codes on timber design.

This presentation aims at updating the strength characteristics of Apa timber, with the following objectives:

(i) Determine the physical and mechanical properties of Nigerian grown Apa timber (Azelia bipindensis)

(ii) Compare the results with other common timber species

(iii) Present an experimental and analytical report including re-grading of the timber were necessary.

\section{BACK GROUND OF THE STUDY}

Apa timber is obtainable in Kwara North, Central and South respectively. With the availability of the timber in the market and its application for structural purposes and the attendant influence on its properties by the changing conditions of soil, weather and other environmental factors, there is need for constant study and regrading to update its properties for designers, engineers and for structural applications. This will ensure safety and economic use of the timber.

\section{MATERIALS AND METHOD}

\subsection{Material Location Area}

Wood samples of Apa timber (Afzelia bipindensis) logs were collected from a forest in Ajase Ipo town, in

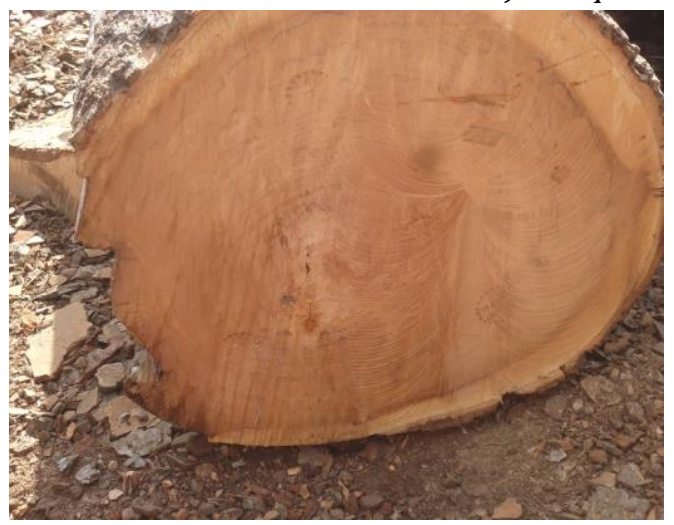

Irepodun Local Government Area of Kwara South [10]. The area lies within latitude $8013^{1} 60 \mathrm{~N}$ and longitude $4^{0} 49^{1} 0$ E. (Google map), with the inhabitants being Yoruba by tribe, farmers and traders.

\subsection{Material Procurement and Preparation}

The material needed for the test is Apa timber stem. The stems were procured at Ajase Ipo area and transported to Irewolede estates sawmill in Ilorin for processing.

\subsection{Processing of Timber for Experiment}

The stems were processed as follow: (a) Sawing: (quartering), (b) seasoning (open air method) and stock piling.

(a) Sawing: A log of Apa wood was $3600 \mathrm{~mm}$ long and $1030 \mathrm{~mm}$ in diameter as shown in Figure 1a. This log from which samples were collected was specially ordered and handled at green state. The $\log$ as shown in Plate I (a) was sawn into commercial sizes and samples were prepared from three marked sections: bottom, middle and top , as shown in Figure 1.

(b) Seasoning and Stockpiling: The split stem long pieces of wood were arranged on one another in the open environment, under the effect of temperature varying from $26{ }^{\circ} \mathrm{C}$ to $33{ }^{\circ} \mathrm{C}$ and atmospheric pressure. The timber was protected from rain and raised off the ground. It was stacked to allow air to circulate freely around all surfaces, reducing the risk of twisting and cupping, as well as minimizing attacks by fungi and insects. The entire length of the log was divided into three regions as Bottom, Middle and Top with samples taken from each longitudinal, radial and tangential direction and from each of these positions, as shown in Figure 1, as specified in [1]. It was ensured that the selected timbers were free of defects and were straight as possible before cutting specimens from them. A total of 324 samples were prepared for this study.

Plate I: Left: Cross section of Apa wood stem before splitting. Right: BS Colour Chart extraction comparison 


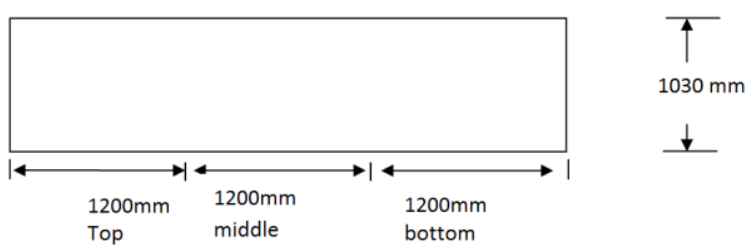

Figure 1 Schematic diagram of stem division

\subsection{Tests for properties}

Specimens for properties tests were prepared following the procedure specified for dimensions as contained in standard codes [1 - 5], In relation to the desired test.

\subsubsection{Physical properties}

(i) Moisture content determination: Moisture content is the amount of water contained in the wood, usually expressed as a percentage of the mass of the oven-dried wood. The percentage of moisture in each sample was determined before the test as described in [1]. Six samples of sizes 50x50x50 mm were collected from bottom, middle and top sections respectively of the log. The moisture content of the samples were determined by weighing the test pieces at green state and after they were oven dried repeatedly in an oven at a constant temperature of $103 \pm 2^{\circ} \mathrm{C}$ until constant values were obtained. The Moisture Content was calculated as expressed C according to [1] in equation (1).

$$
M C(\%)=\frac{\text { original mass }- \text { ovendry mass }}{\text { ovendry mass }} \times 100
$$

(ii) Density determination: Density is a measure of the wood substance contained in a given volume in accordance to the British, Nigerian and European codes $[1,2,4,5]$. Its expression is given in equation (2).

$$
\rho=\frac{\text { Mass }}{\text { Volume }} \mathrm{g} / \mathrm{cm}^{3}
$$

The same sample sizes and numbers were prepared for density determination as used for moisture content determination. Six samples of sizes $50 \times 50 \times 50 \mathrm{~mm}$ were collected from bottom, middle and top sections respectively of the log. Density of the samples was calculated as the ratio of mass of sample to their corresponding volume, as expressed in Equation (2).

(iii) Specific gravity: Specific gravity of wood is the weight of any given volume of a substance divided by the weight of an equal volume of water in accordance to $[1,2,3,4,5,11]$. Six samples of sizes $50 \times 50 \times 50 \mathrm{~mm}$ were collected, respectively, from each longitudinal, radial and tangential direction and from each bottom, middle and top section of the log, making a total of 54 samples for each property. The specific gravity of the samples was determined as:

$$
S G=\frac{\text { weight of sample }}{\text { weight of equal volume of water }}
$$

(iv) Volume shrinkage test: Volumetric shrinkage represents changes in dimension due to decrease in moisture contents. For volume shrinkage, 6 samples each of specimen from each longitudinal, radial and tangential directions and from bottom, middle and top third, respectively were used, but the sizes was $20 \times 20 \times 60 \mathrm{~mm}$ as specified [12]. Its expression is given in equation (4).

$$
\operatorname{VS}(\%)=\frac{\mathrm{VA}-\mathrm{VB}}{\mathrm{VB}} \times 100
$$

Shrinkage rate $=\frac{\text { Average } \% \text { shrinkage }}{\text { Average } \% \text { moisture content }}$ $\mathrm{V}_{\mathrm{A}}=\left(\mathrm{L}_{\mathrm{A}}\right)\left(\mathrm{W}_{\mathrm{A}}\right)\left(\mathrm{t}_{\mathrm{A}}\right)$ is the air dry volume; and $\mathrm{V}_{\mathrm{B}}=$ $\left(L_{B}\right)\left(W_{B}\right)\left(t_{B}\right)$ is the oven-dry volume; where $L_{A}$, $L_{B}$, are lengths, $W_{A}, W_{B}$ are widths and $t_{A}, t_{B}$ are thicknesses

(v) Swelling test: Swelling represents changes in dimension due to increases in moisture contents Equipment: a bowl of water, weighing balance and digital micrometer. Five samples each of radial, tangential and longitudinal from bottom, middle and top positions, were used, but their sizes were each $20 \times 20 \times 60 \mathrm{~mm}$. The weight and dimension of samples were taken and recorded.

(a) The samples were soaked in water and their weights recorded, at 3-days interval until there was no change in weights.

(b) The dimension of the samples were measured at the end of the test. Expression for swelling is given by

$$
\% \text { swelling }(\mathrm{s})=\frac{\mathrm{VB}-\mathrm{VA}}{\mathrm{VA}} \times 100
$$

Where $V_{A}$ is the initial volume expressed as is the $\left(L_{A}\right)\left(W_{A}\right)\left(t_{A}\right) V_{B}$ is the final volume given as is the $\left(L_{B}\right)\left(W_{B}\right)\left(t_{B}\right), L$ is the Length of sample, $B$ is the Width of sample and $t$ is the thickness of sample

\subsubsection{Mechanical Properties}

(a)Equipment and Standard: The determination of various strength properties were carried out in accordance with BS 373 [1] (Method of Testing Small Clear Specimens of Timber). The strength tests were carried out with the aid of a Universal Testing Machine having a maximum load capacity of 50KN at the University of Ilorin, Nigeria, Mechanical Engineering laboratory. For the purpose of this work, 
all strength tests carried out on the wood samples were with the aid of a Universal Testing Machine. Each test was done with the use of special mechanical attachment meant for the test. Samples used for the strength tests in the course of this project were prepared in accordance with BS 373 [1]
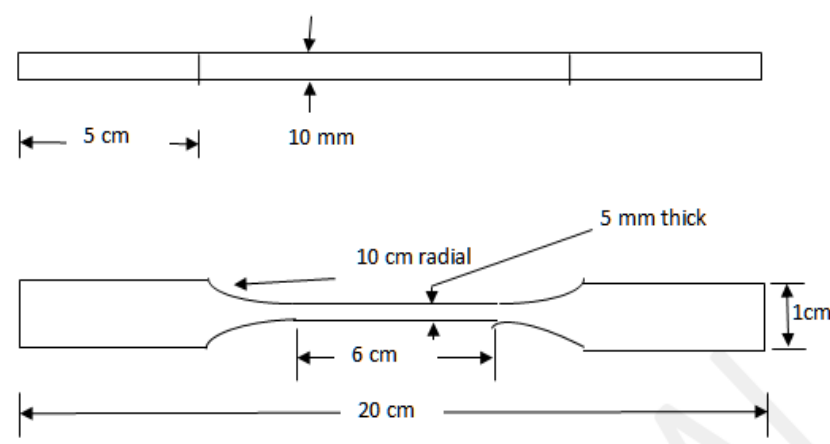

Figure 3: Tensile test sample geometry

(c) Tension parallel to grain test: Six specimens from each axis (radial tangential and longitudinal) and along the stem length (bottom, middle and top) were cut from divisions of log of individual wood. Due to the capacity of the universal testing machine, the cross-sectional area of the test specimen was adjusted to suit the machine capacity as shown in Figure 3. The test piece was as specified in its (machine) manual with the load rate of $1 \mathrm{~mm} / \mathrm{min}$ [1] at constant rate until a sudden sound was heard which indicates breakage of the sample as shown in Plate II (b), and with respect to visual assessment of the specimen tension resistance regarding the existence of defects. The loading equipment used was capable of measuring and plotting the stress -

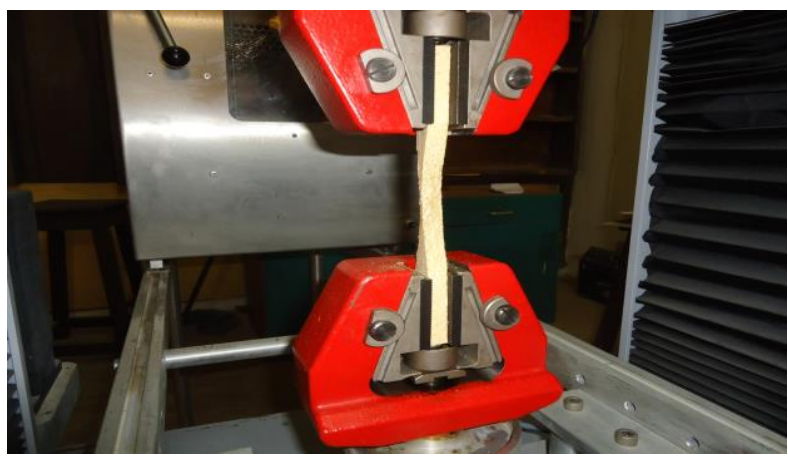

Plate II (a) Test set up for Tensile strength

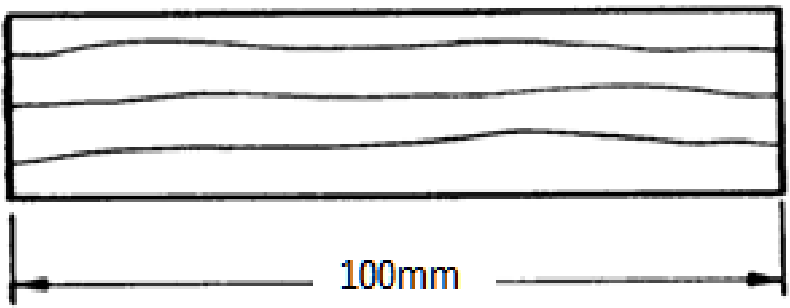

strain curve to the required accuracy of $1 \%$ of the applied load. Tensile specimens thicknesses used were limited to $10 \mathrm{~mm}$ because the machine grip jaws cannot open beyond $10 \mathrm{~mm}$. Afterwards, tensile strength parallel-to-grain was calculated using Equation (6) [1]:

$T S=\frac{\text { Force at failure }(\mathrm{N})}{\text { Minimum Cross }- \text { sectional area }\left(\mathrm{mm}^{2}\right)}$

(d) Compression strength-parallel to grain: Samples used for the compression parallel-to-grain tests were cut from the log. Six samples each were prepared from three directions and positions as explained before. Based on machine capacity and [1], samples were tested in rectangular crosssections of $25 \times 25 \times 100 \mathrm{~mm}$ dimensions as shown in Figure 4. The loading plates approach each other at a constant rate of $0.300 \mathrm{~mm} / \mathrm{min}$ as specified in [1], as shown in Plate III. After each test, the maximum compressive strength parallel-to-grain was read directly from the recorded printout chat. The testing machine automatically divided the load sustained during the test with the cross sectional area of the specimen, before recording it as a stress value on the chart. Maximum compressive strength parallel-to-grain is normally expressed in $\mathrm{N} / \mathrm{mm}^{2}$ Maximum compressive strength (CS) parallel-tograin was calculated by $[1,12]$ :

$$
C S=\frac{\text { Force at failure }(\mathrm{N})}{\text { Cross }- \text { sectional area }\left(\mathrm{mm}^{2}\right)}
$$

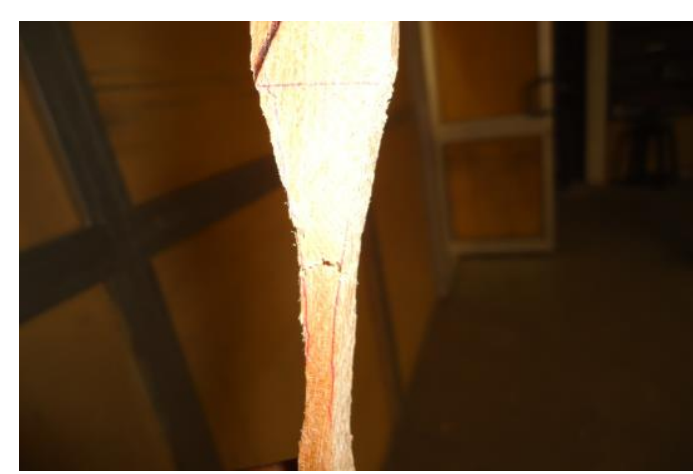

(b) Failure mode showing crack

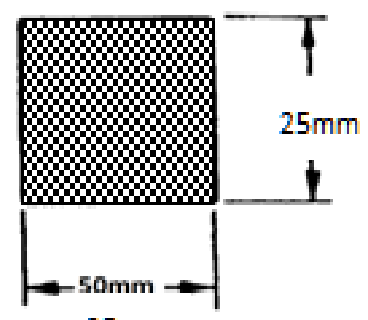

$25 \mathrm{~mm}$

Figure 4: Compression parallel to grain sample: longitudinal and transverse. 


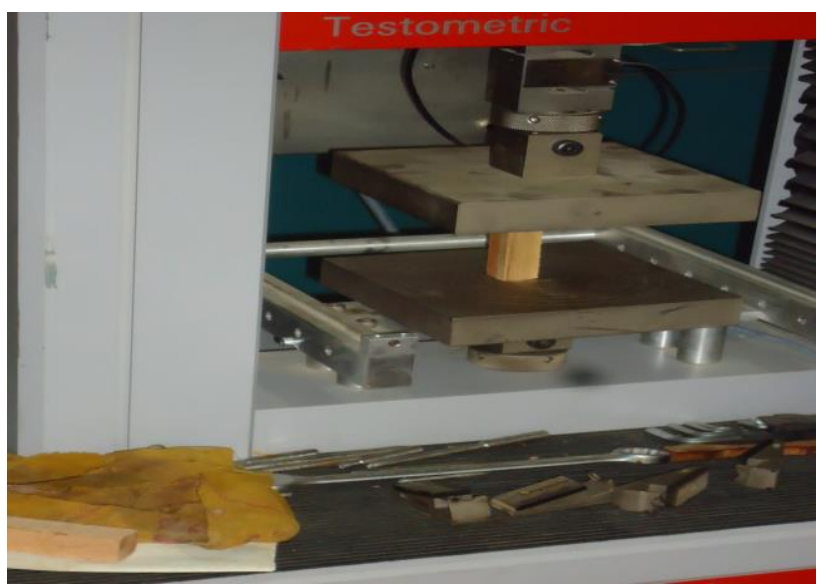

Plate III: Compression test set up

(e) Bending strength: Preparation of Samples: Six Samples (each from bottom, middle and top), each of length $300 \mathrm{~mm}$, breadth $25 \mathrm{~mm}$ and depth $25 \mathrm{~mm}$ were carefully removed from the stem as shown in Figure 5. According to [1], the test samples were placed on supports with a distance of $280 \mathrm{~mm}$ between them that is $140 \mathrm{~mm}$ between the point of application of load and the nearest support. The load was applied centrally to each specimen, which was supported over a span of $280 \mathrm{~mm}$ [1] as shown in Plate IV (a). Deflection and other parameters of the specimen during the tests were saved by the attached computer to the machine. The test speed used was $2.5 \mathrm{~mm} / \mathrm{min}$ [1] and the failure mode is shown in Plate IV (b). Bending strength was calculated from the maximum force obtained using:

$$
\text { Bending }- \text { strength }=\frac{3 F a}{b d^{2}}
$$

In (8), $\mathrm{F}$ is the maximum load applied, a is the distance between load and the nearest support, $b$ is the width of cross-section and, $\mathrm{d}$ is the depth of cross-section.

(f) Shear parallel to grain: The $50 \mathrm{~mm}$ by $50 \mathrm{~mm}$ specimen size was used. The size of specimen is in accordance with provision in BS 373, with the specimen held in position with a E-shaped clamp. The load is centrally applied through a thick steel plate from the upper machine plate. 45 specimens were prepared.

The shear stress is calculated using equation (9)

$$
\sigma=\frac{P}{A}
$$

In (9), $\mathrm{P}$ is the applied load and $\mathrm{A}=\mathrm{bh}, \mathrm{b}$ and $\mathrm{h}$ are the width and depth of the loaded portion, respectively.

(f) Compression perpendicular to grain. The set up is shown in Figure 7 . The test procedure is as stipulated in BS 373 [1]. 45 specimens were prepared.

\section{RESULTS, ANALYSIS AND DISCUSSION}

Result of physical and strength properties

\subsection{Physical properties}

Physical properties investigated are density, specific gravity, swelling, and volumetric change The results are shown in Table 1.

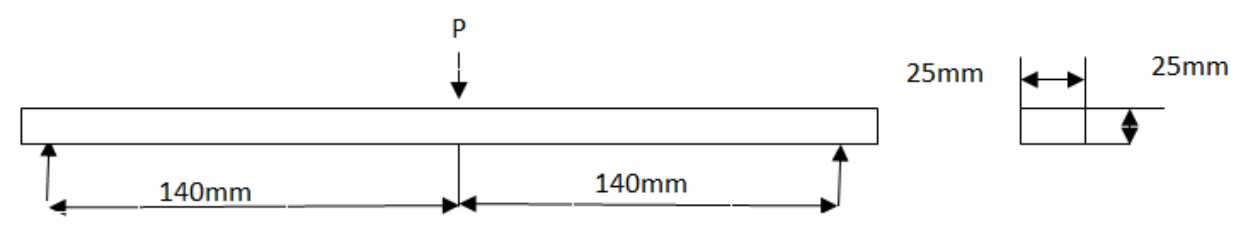

Figure 5: Bending strength test arrangement

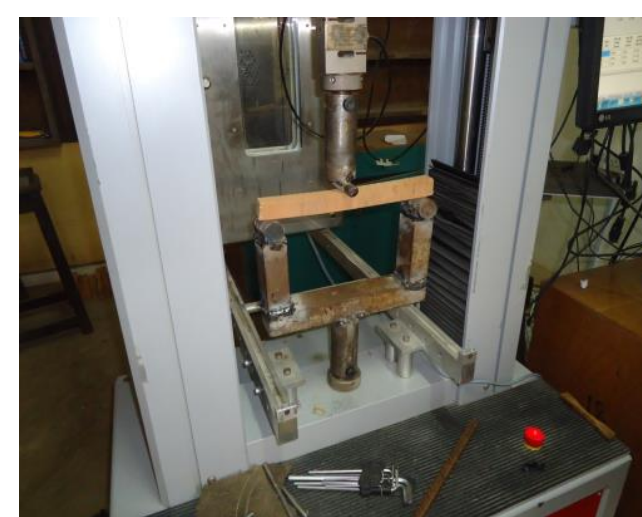

Plate IV: (a) Bending strength test set-up

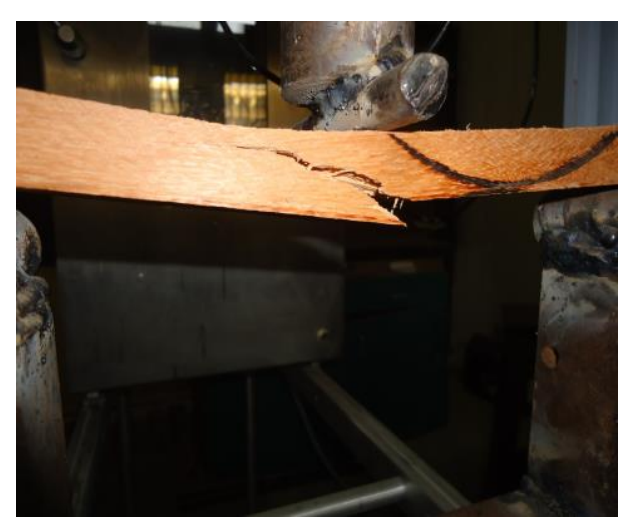

(b) Failure mode 


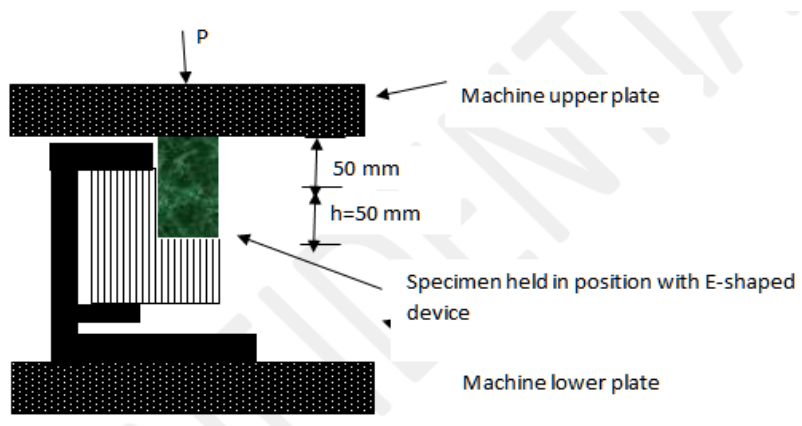

Figure 6 Schematic diagram for shear parallel to grain set up and nominal size

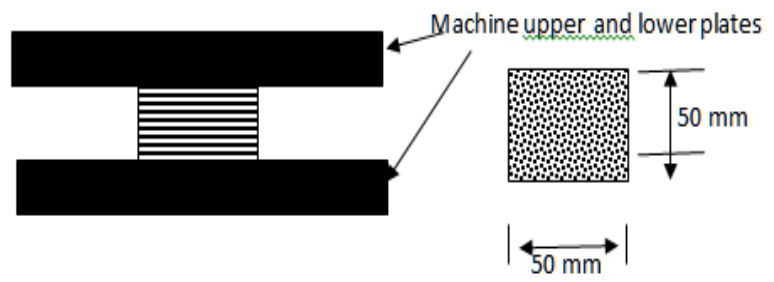

Figure 7: Schematic diagram for compression perpendicular to grain test set up and nominal size

\subsection{Mechanical properties}

The result of mechanical properties obtained from test at an average M.C of $12 \%$ was converted to $18 \%$ M.C. as specified for northern Nigeria. Conversion of the stresses from $12 \%$ M.C. to $18 \%$ M.C. was carried out for strength using Equation (9) $[3,9,13]$, for the purpose of design.

$$
F_{12}=F_{w}(1+\alpha(W-12)
$$

Here, $\mathrm{F}_{12}$ is the ultimate strength at $12 \% \mathrm{MC}, \mathrm{W}$ is the Moisture content at test and $\mathrm{F}_{\mathrm{w}}$ is the ultimate strength at test and $\alpha$ is the proportion of decrease in mechanical property per $1 \%$ increase in moisture content, below the fibre saturation point and $\mathrm{W}$ is : $8<\mathrm{W}<25 \%$ ( $\alpha=0.06$ for compression parallel to grain, 0.04 for modulus of rupture, 0.055 for compression perpendicular to grain, 0.03 for shear parallel to grain and 0,02 for modulus of elasticity) $[14,15]$.

The mean stresses and standard deviation recorded for Apa timber species at an average moisture content of $12.1 \%$ from tests in the laboratory for tensile and compressive parallel to grain, static bending, compression perpendicular to grain and shear parallel to grain were converted to $12 \%$ and $18 \%$ moisture, respectively, as specified for timber design in northern Nigeria [3]. The results are shown in Table 2.

Basic stresses computation: Basic stress is defined in [3] as stress which can safely be permanently sustained by timber containing no strength reducing characteristics that is defect free specimen. This is given by:

$$
f_{b}=\frac{f_{m}-x s}{k}
$$

Here $\mathrm{f}_{\mathrm{m}}, \mathrm{x}, \mathrm{s}$ and $\mathrm{k}$ are mean stress, a multiplier on standard deviation, standard deviation and a factor of safety, respectively. The numerator in the right hand side of equation (10) is the characteristic strength defined statistically as the lower limit which is the strength exceeded by $99 \%$ of the sample strengths [15, 16]. When this is divided by safety factor gives the basic stress. $\mathrm{X}=2.33$ for all properties but $\mathrm{k}=1.4$ for only compression parallel to grain and 2.25 for other properties while no reduction factor is applied on modulus of elasticity [16]. The result of basic stresses is given in Table 2.

\begin{tabular}{|c|c|c|c|c|c|}
\hline Properties & Bottom third & Middle third & Top third & Average & Average (18\% m.c.) \\
\hline Moisture Content & 14.95 & 11.01 & 10.33 & 12.1 & 18 \\
\hline Density & 0.74 & 0.68 & 0.63 & 0.68 & 1.01 \\
\hline Specific Gravity & 0.98 & 0.97 & 0.94 & 0.96 & 1.43 \\
\hline Swelling Test & 9.68 & 8.95 & 8.16 & 8.93 & 13.28 \\
\hline Volumetric Shrinkage & 7.53 & 9.27 & 12.10 & 9.60 & 14.28 \\
\hline
\end{tabular}

Table 1: Some of the physical properties of Apa timber grow $n$ in Kwara State

Table 2: Mean failure stresses, standard deviation and basic stresses for Apa timber

\begin{tabular}{lccccc}
\hline $\begin{array}{l}\text { Types of Stresses } \\
\left(\mathrm{N} / \mathrm{mm}^{2}\right)\end{array}$ & $\begin{array}{c}\text { Mean failure stress at } \\
\text { experimental }(\mathrm{MC}=12.1 \%)\end{array}$ & $\begin{array}{c}\text { Mean Failure Stress } \\
\text { at } 12 \%\left(\mathrm{~N} / \mathrm{mm}^{2}\right)\end{array}$ & $\begin{array}{c}\text { Mean Failure Stress } \\
\text { at 18\% }\left(\mathrm{N} / \mathrm{mm}^{2}\right)\end{array}$ & $\begin{array}{c}\text { Standard } \\
\text { deviation } \\
\left(\mathrm{N} / \mathrm{mm}^{2}\right)\end{array}$ & $\begin{array}{c}\text { Basic stress } \\
\left(\mathrm{N} / \mathrm{mm}^{2}\right)\end{array}$ \\
\hline $\begin{array}{l}\text { Shear parallel to grain } \\
\begin{array}{l}\text { Compressive stress } \\
\text { perpendicular to grain }\end{array}\end{array}$ & 9.73 & 9.76 & 8.24 & 2.65 & 1.59 \\
$\begin{array}{l}\text { Tensile stress parallel to } \\
\text { grain }\end{array}$ & 13.48 & 13.55 & 10.14 & 3.06 & 2.85 \\
$\begin{array}{l}\text { Modulus of rupture } \\
\begin{array}{l}\text { Compressive stress } \\
\text { parallel to graun }\end{array}\end{array}$ & 69.26 & 69.61 & 53.27 & 18.83 & 11.28 \\
Modulus of Elasticity & 87.04 & 87.48 & 66.95 & 24.86 & 13.14 \\
\hline
\end{tabular}


Table 3: Confidence Limits of Apa

\begin{tabular}{llll}
\hline Property & $95 \%$ Confidence Limit & 99\% Confidence Limit & Mean from Test \\
\hline Shear parallel to grain & $9.00-11.43$ & $8.77-12.19$ & 9.73 \\
Compressive stress perpendicular to grain & $12.63-16.06$ & $12.37-17.14$ & 13.48 \\
Tension parallel to grain & $64.25-74.28$ & $62.66-75.86$ & 69.26 \\
Modulus of rupture & $80.41-93.67$ & $81.48-92.60$ & 87.04 \\
Compressive stress parallel to grain & $27.10-30.10$ & $27.34-29.86$ & 28.60 \\
\hline
\end{tabular}

From the result in Table 2, the basic stresses obtained in this research show slight difference with the one recorded by $[4,9,10]$, for some hardwood. Tensile and Bending Stresses parallel to grain are (11.28 and 13.14) $\left(\mathrm{N} / \mathrm{mm}^{2}\right)$ respectively for Apa timber, (19.78 and 20.62) $\left(\mathrm{N} / \mathrm{mm}^{2}\right)$ for Abura timber and bending stress of $37.45\left(\mathrm{~N} / \mathrm{mm}^{2}\right)$ for Ekki timber.

Confidence Limit of $95 \%$ and $99 \%$ for Mean Failure Stresses at $18 \%$ M.C was calculated using statistical Equation (11) for the upper and lower limits [17]

$$
f_{m} \pm t_{\frac{\alpha}{n}, n-1} \frac{S}{\sqrt{n}}
$$

In (11), $\mathrm{f}_{\mathrm{m}}$ is sample mean, $\alpha$ is the level of significance, $\mathrm{S}$ is the sample standard deviation, $\mathrm{n}$ is the number of sample and $\mathrm{t}_{\alpha / 2, \mathrm{n}-1}$ is read in distribution table.

The top third specimens have the highest Modulus of Rupture of $138.801 \mathrm{~N} / \mathrm{mm}^{2}$ followed by middle third and bottom third that is $121.705 \mathrm{~N} / \mathrm{mm}^{2}$ and 81.608 $\mathrm{N} / \mathrm{mm}^{2}$ respectively, which is different from other timber spices and MOE of 12128.795, 11105.036 and $8881.775 \mathrm{~N} / \mathrm{mm}^{2}$ for top, middle and bottom respectively. In this study, it was observed that the low value of MOR at the bottom of the Apa log, as against what is observed in Pinus patula, according to [17], having high value of MOR in the bottom, middle and top as $109.36,87.55$ and $83.74 \mathrm{~N} / \mathrm{mm}^{2}$ and MOE. One of the studies made by Jamatala et. al [19], was that timber for structural use should have MOE of between 6260 and14700 N/mm², MOR of $39-132 \mathrm{~N} / \mathrm{mm}^{2}$ and should be durable. In this study Afzelia bipindensis wood had properties within the specified ranges, thus can be used for making structural elements such as tie beams, rafters and purlins in roof truss construction. According to Jamala et. al [19], they had earlier recorded the following properties of Modulus of Rupture and Modulus of Elasticity of some timber as follows: Celtis mildbraedii (149.94 and 7088.69) $\mathrm{N} / \mathrm{mm}^{2}$; Afzelia Africana (136.71 and 6313.58) $\mathrm{N} / \mathrm{mm}^{2}$; Khaya ivorensis (94.82 and 8192.54) N/mm²; Meliceae excels (90.41 and 5765.63) $\mathrm{N} / \mathrm{mm}^{2}$; and Triplochiton scleroxylon (30.87 and 3937.50) N/ $\mathrm{mm}^{2}$. From this study, it can be deduced that Afzelia bipindensis has a a MOR and MOE of 66.95 and 9577 $\mathrm{N} / \mathrm{mm}^{2}$ at $18 \%$ M.C which is higher than all other timber suggested by Jamala et. al [19]. The range for mean density for the Afzelia Africana species obtained in this study is from 0.63 for top third to 0.74 for bottom third. This agrees with mean density of 718 $\mathrm{kg} / \mathrm{m}^{3}$ and $716 \mathrm{~kg} / \mathrm{m}^{3}$ obtained by Akpan, et.al [20] and Ogunwusi, et. al [21], respectively.

\subsection{Classification of Apa timber}

Comparing the basic stress in Table 2 in this study and the Dry Basic Stress in Table 7 of NCP 2 [3], Apa timber in this study falls into $\mathrm{N}_{6}$ strength group where in [3], dry basic bending and tension parallel to grain are each 9.0, compression parallel to grain is $7.1 \mathrm{~N} / \mathrm{mm}^{2}$, shear parallel to grain is 1.49 , compression perpendicular to grain is 2.00 , and mean value modulus of elasticity is $6300 \mathrm{~N} / \mathrm{mm}^{2}$. The result of mean stresses and basic stresses in Table 2 have shown the effect of magnitude of standard deviation on basic stress. For example, the mean tensile stress parallel to grain of $69.26 \mathrm{~N} / \mathrm{mm}^{2}$ is about 6 times its basic stress of $11.28 \mathrm{~N} / \mathrm{mm}^{2}$. Thus the wide variation of property is one of the causes of the fall in classification of Apa timber from $\mathrm{N}_{2}$ in [3] to $\mathrm{N}_{6}$ in this study. In the same way, based on the British Standard, comparing values in Table 2 and values in Table 8 of BS 5268 [4], Apa timber in Kwara State can be classified into the strength group D30.

\section{CONCLUSION}

Apa (Afzelia bipindensis) timber grown at the periphery of the south western part of the north central region in Nigeria has been successfully re-graded. There is no much difference in properties at the bottom, middle and top portions. Only higher strength values were observed at the middle part. The results of this work will help Structural Engineers to design timber structures in that area using the data suggested herein.

\section{ACKNOWLEDGEMENT}

The authors wish to thank the Technologists in the Wood Work shop and the UTM machine laboratory, in the Faculty of Engineering and Technology, University of Ilorin for their various assistance in the fabrication 
of the specimens and the operation of the testing machine, respectively.

\section{REFERENCES}

[1] British Standards Institution Methods of Testing Small Clear Specimens of Timbers. BS 373. BSI. London 1957.

[2] Booth, L.G. and Reece, P. D.: The structural Use of Timber, A Commentary on the British Standard Code of Practice CP 112, E \& F.N. SPON LTD, London. 1967.

[3] Nigerian Standard Code of Practice, NCP 2: The Use of Timber for Construction, Nigerian Standard Organization, Federal Ministry of Industries, Lagos, Nigeria. 1973.

[4] British Standards Institution; Structural use of timber-Part 2: Code of practice for permissible stress design, materials and workmanships. BS 5268-2. Fifth edition. BSI. London. 2002.

[5] European Standards EN 1995-1-1: Eurocode 5: Design of timber structures - Part 1-1: General Common rules and rules for buildings, The European Union, UK. 2004.

[6] Eliska, B., "Constitutive Model of Timber", Master Thesis, Faculty of Engineering, Department of Mechanics, Czech Technical University in Prague, 2013.

[7] Raji, M. A., Architecture and Emerging Cities: The Impact of Technological Change in Building Material:A Study of Minna, Nigeria 2013.

[8] Okon, K. E., "Variation in Specific Gravity and Shrinkage in wood of a 25 - year old", Gmelina arborea in Oluwa Forest Reserve, South West Nigeria, Scholar Research Library 6(4), pp. 271 276, 2014

[9] Aguwa. J. I.: Reliability Assessment of the Nigerian Apa (Afzelia Bipindensis) Timber Bridge Beam Subjected to Bending and Deflection Under the Ultimate Limit State of Loading, International Journal of Engineering and Technology, Volume 2, No. 6, 2012, pp. 1076-1088. 2012.

[10] Abdulrahaman, A. A., Ihaza, O. C., and Oladele. F. A., "A Survey of some Economic Trees and their Exploitation in Irepodun Local Government Area of Kwara State, Nigeria", Biological and Environment Sciences Journal for the Tropics 6(1), pp. 57-60. 2009.

[11] Perera, P. K. P., Amarasekera, H. S., and Weerawardena, N.D.R., "Effect of Growth Rate on
Wood Specific Gravity of Three Alternative Timber Species in Sri Lanke; Swietenia macrophylla, Khaya senegalensis and Paulownia fortune" , Journal of Tropical Forestry and Environment Volume 2. No. 01. pp. 26 - 35. 2012.

[12] ASTM, American Society for Testing and Materials. ASTM D143. Standard Methods of Testing Clear Specimen of Timber. ASTM D143. Philadelphia. 1987.

[13] Aguwa. J. I. "Structural Reliability of the Nigerian Grown Abura Timber Bridge Beam Subjected to Bending and Deflection Forces" Nigerian Journal of Technology, Vol.32. No. 2, 2013 , pp. 241-252. 2013.

[14] Karlsen, G. and Slitskouhov, Y. U., Wooden and Plastic Structures Mir Publishers Moscow, USSR, 1st Edition, pp 400, 1989.

[15] Jozsef, B. and Benjamin, A. J., Mechanics of wood and wood composites, Van Nostrand Reinhold Company, New York, pp. 558, 1982.

[16] Desch, H. E., Timber properties, $6^{\text {th }}$ Edition, Revised by J. M. Dinwoodie. Macmillan Education Ltd, London, pp 202. 1991.

[17] Aguwa, J. I, and Sadiku, S.. "Reliability Studies on the Nigerian Ekki Timber as Bridge Beam in Bending under the Ultimate Limit State of Loading", Journal of Civil Engineering and Construction Technology. Vol. 2(11), 2011, pp. 253-259.

[18] Zelalem, G., Pradeep, P., and Omprakash, S., "The Influence of Physical and Mechanical Properties on Quality of Wood Produced from Pinus patula Tree Grown at Arsi Forest", Advanced Research Journal of Plant and Animal Science Vol. 2(4), pp. 032-041. 2014.

[19] Jamala, G. Y. , Olubunmi, S. O., Mada, D. A. and Abraham, P., "Physical and Mechanical Properties of Selected Wood Species in Tropical Rainforest Ecosystem, Ondo State, Nigeria", IOSR Journal of Agriculture and Veterinary Science. 5(3), 2013, pp 29-33.

[20] Akpan, M., Olufem, B. and Maiguru, A. A. Density and shrinkage properties of Apa (Afzelia africana) wood in Taraba State Nigeria, Proligno Journal, 9(4), pp 623-630. 2013.

[21] Ogunwusi, A. A., Onwualu, A. P. and Ogunsanwo, 0. Y. , Comparative Analysis of Wood Properties of Afzelia Africana and Anogeissus leiocarpus growing in Nigeria, Chemistry and Materials Research, 3(3) 2013. 